\title{
Type 1 diabetes
}

National Diabetes Information Clearinghouse (NDIC)

\section{Definitions}

Blood glucose level

Defined by National Diabetes Information Clearinghouse (NDIC)

Insulin

Defined by National Diabetes Information Clearinghouse (NDIC)

Immune system

Defined by National Diabetes Information Clearinghouse (NDIC)

Beta cell

Defined by National Diabetes Information Clearinghouse (NDIC)

\section{Pancreas}

Defined by National Diabetes Information Clearinghouse (NDIC)

\section{Source}

National Diabetes Information Clearinghouse (U.S.). (2009). The diabetes dictionary. [Bethesda, Md.]: U.S. Dept. of Health and Human Services, National Institutes of Health, National Institute of Diabetes and Digestive and Kidney Diseases, National Diabetes Information Clearinghouse.

A condition characterized by high blood glucose levels caused by a total lack of insulin. Occurs when the body's immune system attacks the insulin-producing beta cells in the pancreas and destroys them. The pancreas then produces little or no insulin. Type 1 diabetes develops most often in young people but can appear in adults. 